\title{
Recommendations for measuring non-image-forming effects of light: a practical method to apply on cognitive impaired and unaffected participants
}

\author{
Citation for published version (APA): \\ van Duijnhoven, J., Aarts, M. P. J., Aries, M. B. C., Böhmer, M. N., \& Rosemann, A. L. P. (2017). \\ Recommendations for measuring non-image-forming effects of light: a practical method to apply on cognitive \\ impaired and unaffected participants. Technology and Health Care, 25(2), 171-186. https://doi.org/10.3233/THC- \\ 161258
}

DOI:

10.3233/THC-161258

Document status and date:

Published: 22/03/2017

\section{Document Version:}

Accepted manuscript including changes made at the peer-review stage

\section{Please check the document version of this publication:}

- A submitted manuscript is the version of the article upon submission and before peer-review. There can be important differences between the submitted version and the official published version of record. People interested in the research are advised to contact the author for the final version of the publication, or visit the $\mathrm{DOI}$ to the publisher's website.

- The final author version and the galley proof are versions of the publication after peer review.

- The final published version features the final layout of the paper including the volume, issue and page numbers.

Link to publication

\footnotetext{
General rights

- You may freely distribute the URL identifying the publication in the public portal. follow below link for the End User Agreement:

www.tue.nl/taverne

\section{Take down policy}

If you believe that this document breaches copyright please contact us at:

openaccess@tue.nl

providing details and we will investigate your claim.
}

Copyright and moral rights for the publications made accessible in the public portal are retained by the authors and/or other copyright owners and it is a condition of accessing publications that users recognise and abide by the legal requirements associated with these rights.

- Users may download and print one copy of any publication from the public portal for the purpose of private study or research.

- You may not further distribute the material or use it for any profit-making activity or commercial gain

If the publication is distributed under the terms of Article $25 \mathrm{fa}$ of the Dutch Copyright Act, indicated by the "Taverne" license above, please 


\title{
Recommendations for measuring non-image-forming effects of light: A practical method to apply on cognitive impaired and unaffected participants
}

\author{
J. van Duijnhoven ${ }^{a, d}{ }^{,}$, M.P.J. Aarts ${ }^{a, d}$, M.B.C. Aries ${ }^{a, b}$, M.N. Böhmer ${ }^{c, e}$ and A.L.P. Rosemann ${ }^{a, d}$ \\ a Eindhoven University of Technology, Department of the Built Environment, Eindhoven, The Netherlands. \\ b Jönköping University, School of Engineering, Department of Civil Engineering and Lighting Science, Jönköping, Sweden \\ ${ }^{c}$ Chair Intellectual Disability Medicine of the Erasmus Medical Center Rotterdam, Rotterdam, The Netherlands \\ d Intelligent Lighting Institute, Eindhoven University of Technology, Eindhoven, The Netherlands \\ e Middin health care provider, Rijswijk, The Netherlands \\ * Corresponding author: J. van Duijnhoven, Eindhoven University of Technology, Department of the Built Environment, P.O. \\ Box 513, 5600 MB Eindhoven, The Netherlands. Email: J.v.duijnhoven1@tue.nl. Tel. no.: 0031- 402475760
}

\section{Abstract}

BACKGROUND: The non-image-forming effects of luminous radiation on people with intellectual disabilities or dementia received attention from researchers. Such studies, however, have generally been conducted using disparate methodologies which precludes generalization and reproducibility.

OBJECTIVE: The aim of this study was to determine the practical applicability of measurement devices for studies investigating non-image-forming effects of luminous radiation, specifically for people with intellectual disabilities or dementia.

METHODS: In three experiments, ten cognitive impaired people and thirty-nine unaffected subjects participated by wearing one or more portable devices. Six devices were assessed in total. Measurement data was accompanied with user experiences obtained from questionnaires, interviews and observations in order to assess the devices on practical and comfort issues.

RESULTS: On average, the devices worn by the cognitive impaired subjects were not experienced as annoying or irritating. No significant differences are found between genders and for one of the portable devices significantly less annoyance was reported by the cognitive impaired participants compared to the unaffected group of participants.

INNOVATIVE SOLUTION: The three phases of the research process in towards measuring personal luminous exposures are: selection of the most suitable portable device, application of the assessment method, and the application of the device in the (pilot) study.

CONCLUSIONS: However, the findings of this study suggest that inaccuracies potentially caused by practical and comfort issues associated with the portable devices need to be considered. 


\section{Keywords}

NIF, non-visual effects, intellectual disability, dementia, cognition, wearables, light measurements.

\section{Introduction}

Lighting conditions can create favourable circumstances for vision but also provoke circadian responses that influence health and well-being aspects of humans. These responses, or so-called nonimage-forming (NIF) effects, can be either acute or circadian. Acute reactions include fluctuations in melatonin secretion, core body temperature, heart rate, brain blood flow and cognitive performance, whereas circadian include circadian phase shifts and changes in sleep patterns which over time might lead to specific behavioural disorders.

Over the last two decades, research $(1,2)$ has investigated the effects of luminous radiation on sleep and behavioural problems (e.g. anxiety or mood swings). The Commission Internationale de l'Eclairage (CIE) clarified the differences between light and luminous radiation in their technical notes(3)'(4). However, the use of significantly different methodologies and equipment between such studies limits the potential for comparison, repeatability, and meta-study. For comparison of results from such studies, significant effort is required for the consideration of differences and similarities of the different methodologies used and a number of assumptions and caveats are unavoidably introduced. The importance of the methodological approaches to this field of research are discussed in a review by van Hoof et al.(5) and later highlighted again in (6). This study developed an approach prior to a field study to eliminate inaccuracies or uncertainties due to methodological differences to measure NIF effects of light.

Multiple measurement devices are available for the measurement of luminous irradiance and effective irradiance levels. Measurement devices can be static room-based or wearable. Room-based measurements must be accompanied by cameras to record the participant's viewing direction and 
precise location of the participant. Ideally, the effective irradiance with respect to the circadian response should be measured at eye level. Luminous radiation that enters the eye and reaches the ipRGCs stimulates NIF effects. The best location for a portable measurement device is at the eye to ensure most accurate measurement results. Due to limitations of room-based measurement methods, and the increased potential for wearable devices to more accurately track luminous exposures at eye level, portable measurement devices are generally preferable. Wearable devices are, however, limited by the requirement to be unobtrusive, such that behaviour by participants is unaffected and thus representative of normal behaviour.

The applicability of a portable device can be marked for performance on variables such as acceptance, comfort, and accuracy. An acceptance-based practical problem might, for example, be that a participant does not want to wear the portable device. Comfort issues could be eye or skin irritation, the burden to carry the device, and the potential to block the wearer's visual field. The loss or damage of a measurement device, the inability of the device to capture luminous radiation (through shadow or clothes), the performance and the measurement errors of the measurement devices itself, and the variable location on the body at which the luminous radiation has been measured are examples of accuracy problems. The study by Markvart and colleagues (7) demonstrated the importance of calibrating the equipment before starting measurements. The focus of the current study is on the accuracy and comfort aspects of the measurement devices.

In this study, six portable photopic measurement devices are assessed on their practical problems and comfort issues. Consideration of these issues should allow for the assessment of the capability of the portable device to be applied during studies investigating sleep and behavioural problems, specifically for cognitive impaired people like people with intellectual disabilities or dementia. 
The goal of the study is to determine the amount of annoyance from different portable devices in three experiments. In experiment 1 , participants wore six devices simultaneously; in experiment 2 , the participants wore two devices simultaneously; and in experiment 3, only one device was worn per participant. Three hypotheses are tested in this study:

1. The amount of annoyance from portable devices differs between the three experiments due to the measurement setup (wearing one, two or more than two devices simultaneously)

2. The amount of annoyance from portable devices differs between genders (gender differences for reporting experiences are highlighted in literature(8));

3. The amount of annoyance from portable devices differs between participants with a cognitive impairment (i.e. intellectual disabilities or dementia) and participants without this challenge (multiple studies $(9,10,11)$ indicated behavioural problems among people with intellectual disabilities).

In experiment 2, participants with a cognitive impairment, specifically people with intellectual disabilities or dementia, are being recruited. This group of people can hardly reflect on the worn portable devices proving it is more difficult to assess the devices on comfort issues within this group of participants.

\section{Methodology}

This section reports the methodology for the assessments of six portable light measurement devices. In order to understand the capabilities of the portable devices, practical problems and comfort issues of each device were investigated. The product names and brands are known to the authors but are not provided in this paper.

Practical problems were determined by analyzing the output data from the portable devices. Missing or distinctive data could be indicative of practical problems of the measurement devices. Practical problems were also identified through observations by researchers. Comfort issues were quantitatively and qualitatively investigated by applying questionnaires, interviews, and observations. 
One of the aspects to determine the applicability of a portable device is the accuracy of the outcomes. The accuracy of the measurement results at different locations on the body was determined in an independent additional study. One person was wearing four identical light sensors on four different locations on the body for one afternoon. 'In the middle of a pair of glasses' was the reference location. Median deviations are calculated from the wrist, chest, and the side of a pair of glasses to the reference location. Considering both the indoor and outdoor data, the inaccuracy of measuring at the wrist was $13-27 \%$, at the chest location $7-17 \%$ and on the side of the glasses $7-8 \%$ (see Table 1 ).

\subsection{Measurement set-up}

The capabilities of the different portable devices were investigated in three experiments that consisted of different participant samples. The first two experiments were performed in spring 2015 and the third experiment in winter 2015.

Twenty-one healthy, unaffected subjects were recruited to participate in the first experiment. The participant sample was recruited via a personal network. The researcher explained the experiment procedure to the participants, without telling them the main research objective. To exclude the possibility that practical and/or comfort problems occur at a specific time of day or with only one of the devices, the participants were asked to wear all six portable devices simultaneously. The devices were worn for a period of approximately two hours.

The participant group for the second experiment consisted of ten subjects with intellectual disabilities

or dementia. The participants were recruited via a collaboration with Erasmus Medical Centre Rotterdam and health care provider Middin based in Rijswijk, the Netherlands. The participants were verbally informed by the researcher about the procedure of the experiment in order to ensure the same procedure in all experiments. Previous studies have already approved the applicability of wrist- 
worn devices by elderly people suffering from dementia or ID (e.g. (9)); therefore, the three wrist-worn devices were excluded from this experiment. Furthermore, another device was excluded from this experiment because it was not commercially available. Thus, those participants wore only two devices simultaneously. Two considerations when working with participants with ID or dementia are that there is likely to be an impairment in the ability to answer reflective questions and that the speed and scope of mobility of participants are likely to be limited. Accordingly, the measurement period was prolonged to four to eight hours compared to the first experiment in order to generate sufficient experience with the devices.

The third study included eighteen office workers wearing one portable device. These participants all work at the Eindhoven University of Technology and were recruited via an online registration form sent out via Email. The main objective of this study was to support the outcomes of the first two experiments. The questionnaire in this study contained four items regarding the device comfort. Only this data will be presented.

\subsubsection{Ethical approval}

In the Netherlands, according to the CCMO(12), there are two circumstances which should be met in a study in order to be obliged to get the ethical approval:

1. It is a medical scientific research project

2. Participants were subjected or asked to specific behaviour or acts.

This study is a medical scientific research project because the applicability of measurement instruments is assessed. However, the researchers did not ask the participants to act or perform a specific behaviour. The participants were able to do their normal daily activities. In conclusion, the two attributes are not meet both. 
This study was prior to a larger field study (Bright-2). In Bright-2, the cognitive impaired participants were asked to wear measurement devices for a longer period of time. This time the real measurement devices were used instead of the placebos used in experiment 2 of this study. Prior to the Bright-2 study, the researchers informed at the Medical Ethics Committee Erasmus MC in Rotterdam whether an ethical approval is mandatory. Their response was that this study did not meet the two regulations; therefore, an ethical approval was not mandatory (MEC-2015-472).

All subjects participating in experiment 1 and 3 provided their written informed consent prior to the execution of the study. The informed consent procedure of experiment 2 was based on work of Hilgenkamp et al. (13). Participants who could make their own decision regarding consent for participation, information consisted of an introductory letter, an information booklet, and a consent form. For participants who were not able to make this decision themselves, their legal representatives were approached, with the same information package. On the day of the experiment, the participants were asked again whether they agreed to participate. One participant in experiment 2 did not want to wear the supplied glasses during the experiment. All other participants fully participated in the experiments. Participants were not compensated for participating in the study and they were able to withdraw from the experiment at any time.

\subsection{Experiment 1}

Twenty-one subjects participated in this experiment ( 12 male and 9 female; mean age $=43.0, \mathrm{SD}=$ 15.6 , range $=[23 ; 72])$. The measurement period was approximately two hours during the day in which the participants were able to do their normal daily activities, such as studying, writing, sitting, or making phone calls. The participants' activities were not restricted to indoor conditions.

Twenty participants wore six devices simultaneously. One device ceased to function during the measurement period for one participant; therefore, this participant will be considered to have only 
worn five devices simultaneously. The six devices were worn at their 'default' locations according to the manufacturers, as follows (see Figure 1):

- Three wrist-worn devices as a watch (ranging from 9 to 25 grams),

- One device as a necklace (18 grams),

- One device attached to the side of a glasses (12 grams), and

- One device as a badge connected to a data logger in a waist bag.

For the three wrist-worn devices, the participants were free to choose on which wrist they prefer to wear the devices. It is assumed that this freedom of choice provides the highest comfort. Participants were not obliged to wear all three wrist devices on the same wrist. For the device attached to the side of a glasses, eight participants were glasses wearers and were able to wear the measurement device attached to their own glasses. The other participants wore the device attached to a pair of provided glasses.

During this experiment, the participants were asked to keep a diary to record their locations, activities, and potential annoyances from the devices to capture practical and comfort issues. Besides keeping a diary, the participants were asked to complete a questionnaire regarding comfort aspects of the portable devices at the end of the measurement period.

\subsection{Experiment 2}

Ten people with ID or dementia participated in this experiment ( 4 male and 6 female; mean age $=64.7$, $S D=9.6$, range $=[52 ; 80])$. Six participants had an ID and four participants had dementia. The ten people resided at two Dutch care facilities: one located in Rotterdam and one in The Hague. The measurement period was four to eight hours, starting from midday until right before the participant had dinner.

This group wore two portable devices simultaneously: one device attached to a pair of glasses and one device as a necklace (respectively device 1 and 5 compared to experiment 1 ). In this experiment, 
placebos of the portable devices were used in order to eliminate the risk of damaging or losing the devices. Five participants need to wear glasses and were able to wear the device attached to their own glasses. Four participants wore the device attached to a provided pair of glasses. One participant refused to wear the supplied pair of glasses and wore only one device during the experiment.

In this experiment, the assessment of the portable devices, measuring practical problems and comfort issues regarding the portable devices, was applied using three methods:

(A) Interviews and questionnaires with the participants;

(B) Questionnaire responses from caregivers of the participants; and

(C) Observations performed by the researchers.

\subsection{Experiment 3}

The third experiment consisted of eighteen employees of the Eindhoven University of Technology (9 male and 9 female; mean age $=35.9, \mathrm{SD}=11.0$, range $=[24 ; 57])$. The participants wore one portable device during the measurement period in order to ensure that the potential comfort issues arose from that specific portable device. In experiment 3, four devices from experiment 1 were worn and assessed. The numbers of participants wearing a specific device are shown in Figure 2. The participants wore the portable devices for one working day of approximately eight hours. Afterwards, they completed a survey containing, among others, questions about the device comfort. Four 7-point scales are used to evaluate the devices (uncomfortable(1)/comfortable(7), painful(1)/pleasant(7), irritating(1)/ untroubling(7), and annoying(1)/satisfying(7) all indicating 7="positive" and "1=negative").

\subsection{Statistical analysis}

All data from the three experiments are analysed using IBM SPSS Statistics version 22. All analysed variables in this study showed not normally distributed data according to Kolmogorov-Smirnov and Shapiro-Wilk tests. Not normally distributed data can be analysed by using non-parametric correlation coefficients and non-parametric statistic tests. Due to small sample sizes and categorical data in nearly 
all experiments $(n<30)$, the independent variable test Chi-Square test is used to investigate differences between groups.

\section{Results}

Similar to the methods section, the results are presented separately by experiment. For each, practical problems and comfort issues of the portable devices are described. The assessed portable devices are referred to by assigned numbers. Not every portable device was able to measure or log effective irradiances with respect to the circadian response; therefore, for each analysis regarding device output, the illuminance is used as the outcome measure instead of the effective irradiance with respect to the circadian response.

\subsection{Experiment 1}

The data of experiment 1 were used to identify a number of practical issues. Clothes or sleeves covering the portable devices was the most important issue addressed. Figure 3 shows the output data from all six worn devices for one participant. This graph displays the relatively low illuminance values for the two wrist-worn devices ( 2 and 6 ) for a large part of the measurement period. Figure 4 also shows that the device on the chest location got covered when the participant went outside. This can be explained by a jacket covering the measurement device.

The comfort issues were investigated using questionnaires. Respondents were asked to indicate whether they experienced discomfort from the portable devices. The majority (67\%) experienced two or more annoyances from the portable devices (see Table 2). From all the questionnaire responses, device 1 was experienced as the most irritating portable device (see Figure 5).

The annoyances from device 1 can be categorized into annoyances from people wearing their own glasses or from people wearing the supplied glasses. Eleven out of the eighteen annoyances from 
device 1 were experienced from participants wearing the supplied glasses. Wearing glasses is an acquired habit, which may explain the high number of complaints from not-glasses-wearers. However, the difference between the number of annoyances from glasses wearers and non-glasses wearers for device 1 is not significant $\left(\chi^{2}(1)=0.359, p=.549\right)$.

The variation in total amount of reported annoyances per gender shows no significant difference between genders $\left(\chi^{2}(3)=7.525, p=.057\right.$; mean male=1.42, mean female=2.22). The differences between the group for the annoyances only from device 1 or only from device 5 were not significant either $\left(\chi^{2}(1)=3.706, p=.054 ;\right.$ mean male $=0.67$, mean female $=1.00$ and $\chi^{2}(1)=0.788, p=.375$, respectively $)$. The difference between genders for the total amount of reported annoyances and for the annoyance only from device 1 are close to the significance level of $p=.05$; therefore, it can be concluded that there might be a noticeable higher number of reported annoyances.

Another analysis performed was whether the choice of the wrist for the wrist-worn devices had any impact on the number of annoyances caused by each device. The devices 2 and 3 were worn: eight times at the left wrist and thirteen times at the right wrist. Device 4 was worn at eighteen left wrists and three right ones. No significant correlation was found between wrist choice and annoyance from that specific wrist-worn device (no annoyances reported from device 2 and $4 ; \chi^{2}(1)=2.154, p=.142$ for annoyance from device 3). It is not investigated whether the reported annoyance was due to the devices itself or due to the fact that they might have worn two or three devices at one wrist.

\subsection{Experiment 2}

In this experiment, four practical problems arose. First, similar to experiment 1 , devices were occasionally covered by sleeves or jackets. Second, in this specific group of people, cognitive impairments are highly important to take into account when choosing a portable light measurement device for a study investigating the NIF effects of luminous radiation. People with ID might have 
difficulties accepting and evaluating the devices, while people with dementia might have memory loss problems. The higher prevalence of memory loss might lead to losing devices, resulting in unreliable measurement data. Third, one participant refused to wear the glasses containing device 1 . Finally, three participants were not able to reflect on the devices via the questionnaire and/or an interview. For those three participants, the questionnaires with the caregivers and the observations will provide information about the participant's comfort regarding the devices.

Besides practical problems, comfort issues were analysed. The total number of reported annoyances from each device differed slightly among the three applied methods. For the dementia group, at most two persons noticed annoyances from device 1 and one person from device 5. For the ID group, the number of people experiencing annoyances was even lower (see Figure 6).

To test the reliability of the three different methods applied (A: questionnaire participant, B: questionnaire caregiver, C: observations), Cronbach's Alpha was calculated for reported number of annoyances from device 1 in method $A, B$, and $C$ and separately for annoyances from device 5 . The set point of a good reliability when combining the methods was chosen at a Cronbach's Alpha of 0.7. Combining the results from all methods for annoyances from device 1 had a low reliability $(\alpha=.500)$ as well as for the annoyances from device $5(\alpha=.462)$. This means that all results from the three methods cannot be combined and need to be interpreted separately.

The differences between groups are analysed in terms of gender and group. There are no significant differences between genders with respect to the amount of annoyance, except the statistically significant difference for the annoyance from device 1 reported by the caregivers (method B) between male and female participants $\left(\chi^{2}(1)=4.444, p=.035\right.$; mean male $=0.00$, mean female $=0.67$ see Table 3$)$. Although, as Figure 6 shows, the participants with dementia reported more annoyances than the participants with ID, this difference is not significant (all $p>.05$, see Table 3 ). 


\subsection{Experiment 3}

To evaluate the portable devices on healthy subjects in this experiment, four items with a 7-point scales were used. To test the reliability of combining those four scales, Cronbach's Alpha is calculated $(\alpha=.711)$, which indicates an assumable reliability. The mean score of those four scales was calculated and categorized as an annoyance or not an annoyance (a mean score lower than 4 is assumed as an annoyance).

As in both previous experiments, also for this experiment, the correlation between annoyance from devices and the gender of the participants is calculated. The difference between the groups male and female, which are calculated using the Chi-Squared test, was not significant $\left(\chi^{2}(1)=0.00, p=1.00\right.$ and $\chi^{2}(1)=1.333, p=.248$ for annoyance from device 1 and annoyance from device 5, respectively). The mean score of device comfort is tested for its correlation with the participant's age. Although this correlation shows a trend that younger people report more annoyances than older people, this correlation is not significant $(\tau=-.27, p=.899)$.

\subsection{Combined datasets}

All data from the three experiments are combined in order to evaluate the three main hypotheses. The differences between groups are investigated using the non-parametric independent samples Chisquared tests.

The differences for the amount of annoyance are calculated between the three experiments: participants wearing one, two or more than two portable devices simultaneously (experiment setups 1, 2 and 3). All three methods of experiment 2 are included. The statistic test is applied separately for annoyance from device 1 and annoyance from device 5. Statistic values of $\chi^{2}(2)=7.159, p=.028$ and $\chi^{2}(2)=0.956, p=.620$ indicate significant differences between the three experiments for the annoyance from device 1 and no significant differences for annoyance from device 5. The Chi-Squared tests are 
also performed calculating the differences between the different experiments in which only one of the applied methods of experiment 2 is taken into account. Table 4 provides the results.

If the methods $A, B$, and $C$ of experiment 2 are separately considered, no statistically significant differences are found for annoyance from both devices between experiments 1,2 and 3 . If all methods of experiment 2 combined are considered and the groups are divided into a number of portable devices worn, only a statistically significant difference is found between the groups and the annoyance from device $1\left(\chi^{2}(2)=7.308, p=.026\right.$; mean 1 device $=0.50$, mean 2 devices $=0.42$, mean $>2$ devices $\left.=0.81\right)$. The means indicate that people experienced more annoyance when they were wearing multiple devices. These differences might be due to the difference in experimental setups or other aspects such as gender or state of health.

The differences between male and female for the number of annoyances from device 1 and device 5 are both statistically insignificant $\left(\chi^{2}(1)=3.115, p=.078\right.$ and $\chi^{2}(1)=0.145, p=.704$ respectively).

To investigate whether there are statistically significant differences between cognitive impaired and unaffected participants and their annoyances from device 1, the Chi-Squared test is applied $\left(\chi^{2}(1)=5.975, p=.015 ;\right.$ mean cognitive impaired $=0.42$, mean unaffected $\left.=0.76\right)$. The same test is applied for the differences between these groups for their annoyances from device $5\left(\chi^{2}(1)=0.145, p=.704\right)$. These statistical tests indicate a significant difference between cognitive impaired and unaffected people for the annoyances from device 1 , but this difference is not significant for the annoyances from device 5. The amount of annoyance from device 1 experienced by the participants suffering from ID or dementia is significantly lower than experienced by the unaffected participants from experiments 1 and 3 . 


\section{Discussion}

The main goal of this study was to determine the applicability of six portable measurement devices for studies investigating NIF effects of luminous radiation, specifically for cognitive impaired. This determination led to a method to select the most suitable device for each specific field study. In order to investigate this applicability, three experiments have been performed.

Experiment 1 consisted of twenty-one participants without cognitive impairments. In all but one case, the participants wore six portable devices simultaneously. The main practical problem was that devices were regularly covered by sleeves, a jacket or shadow. The comfort issues were investigated using questionnaires. Sixty-seven percent experienced annoyances from two or more portable devices and device 1 (attached to the glasses) was experienced as the most irritating portable device. There was not a significantly meaningful influence from whether participants wore their own or the supplied pair of glasses or from the choice of the wrist for devices to be worn on.

In experiment 2, nine people with ID or dementia wore two portable devices simultaneously, the devices referred to as device 1 and device 5 from experiment 1 . One participant only wore one device. Device 5 received on average positive feedback and the experience of device 1 was mostly negative in experiment 1. During this experiment, more practical problems arose compared to experiment 1; besides covering the devices with clothes, this particular group of participants lost, broke, or forgot (to wear) the devices more easily. Those practical problems have led to unreliable output data from the portable devices. Losing, breaking or forgetting to wear a device could also be an acceptance or comfort problem of the participant regarding that portable device. To investigate comfort issues from the portable devices in this experiment, three methods were applied. Cronbach's Alpha of .3 indicated that the results of those three methods cannot be combined for further analysis. The majority of the participants in experiment 2 experienced only minor comfort issues from the two devices. The results 
show that in terms of comfort, those two portable devices are suitable for this specific group of participants.

Experiment 3 was performed to exclude the possibility of annoyances resulting from the act of wearing multiple devices simultaneously. In this experiment, eighteen participants wore only one device. Four people wore device 1, and four people wore device 5 (which are also used in experiments 1 and 2). The device comfort is investigated using four seven-point scales. Cronbach's Alpha of .711 suggested a correspondence between all scales and approved the possibility to merge the four scales. The mean score of device comfort (average of the four scales) is not significantly correlated with the participant's age.

Apart from determining the practical applicability of the portable measurement devices, the experiment described in the methodology section investigating the differences in photometric measures output between four locations on the body is of high importance. The current study is in accordance with the work of Figueiro et al. (14) in which this difference is highlighted. They indicated that the magnitude of differences between the device locations is quite large; therefore, this result underscores the potential problems in measuring light exposures at the wrist. In addition to Figueiro's paper, Hubalek et al. (15) developed a measurement device measuring luminous exposure near the eye which highlights the importance of measuring at the right location.

This study had two limitations that restrict the generalizability of the findings. Firstly, the results are based on twenty-one and ten participants in experiment 1 and 2 respectively. More comprehensive conclusions can be drawn with a larger sample. Secondly, in experiment 1 and 2 , the annoyances were investigated using questionnaires resulting in categorical data. This data cannot be analyzed as comprehensively as the 7-point scale answers from questionnaires. 
Besides the limitations, this study also identified strengths. In case the participants were notified with the goal of the study, namely to investigate NIF effects of luminous radiation by measuring the effective irradiance and exposure through portable devices, the participants' level of annoyance might be lower due to their potential benefit from it. It is assumed that if people know what the goal is and that goal is attractive to them as well, they are more willing to participate and will presumably report less annoyance from the devices.

In this study, people with ID or dementia were the main target group. Performing studies investigating the NIF effects of luminous radiation on cognitive impaired people is assumed to be more difficult than on a group of healthy subjects. As assumed and indicated in experiment 2, this group has more practical problems wearing and accepting the portable devices. The results regarding the comfort issues between those groups indicate that cognitive impaired people reported fewer annoyances compared to healthy subjects. The results from this study can be applied to all other studies investigating NIF effects from luminous radiation because the assumed most challenging group is already investigated. Possible practical implications are luminous radiation measurements of employees in office buildings or children in schools.

\section{Innovative solution}

This study assessed six existing portable light sensors intended to be used for studies investigating NIF effects of light at individual level. The assessment led to new insights into the whole research process that must take place prior to a field study. The three phases of this research process are: selection of the technically most suitable portable device, application of the assessment method specifically for the target group, and application of the device in the field study to investigate NIF effects of light on the target group.

\section{Phase 1: Selection of the most suitable portable device}


An additional experiment in this study indicated deviation percentages ranging from $7 \%$ to $27 \%$ when the luminous exposure is measured at the wrist, chest, or side of the head, compared to the position in between both eyes. These deviations highlight the discrepancy of measuring at different locations. Selecting the most suitable portable device depends on the (target group of the) study. In studies aiming at quantitative results, the accuracy related to these deviations will be the most important aspect; for studies focussing on indicative or qualitative research questions, aspects of comfort or applicability are more important.

Phase 2: Application of the assessment method specifically for the target group

The selected portable device needs to be tested on comfort and other practical issues. Practical issues can be revealed by analysing the output data from the portable device. Two recommendations to reduce the number of practical issues are:

- Intensive supervision of the participants in order to check whether they are still wearing the device properly;

- Performance of the assessment study under warm conditions in order to be able to ask the participants to wear short sleeves, to prevent the main practical problem 'covering the device'.

Comfort issues can be identified by questionnaires, interviews or observations. In case the participant is unable to answer reflective questions, it is recommended to ask the participant's caregiver of the participant or to observe the participant intensively and, for example, count the number of visible irritations.

\section{Phase 3: Application of the device in a field study to investigate NIF effects of light}

After phase 1 and 2, and only then, the device is ready to be used in a field study to explore potential NIF effects related to the individual luminous exposure. 
This newly developed research process needs to be followed in its entirety in order to ensure that the data collected by a portable device is adequate and accurate enough to draw conclusions about the luminous exposure of the participants. Following this suggested also allows other researchers to understand, replicate, and compare the research results. The importance of this possibility to be able to interpret or repeat the results is highlighted in the paper of van Hoof and colleagues (5).

\section{Conclusions and recommendations}

The results of this study show significant differences between the three applied experiments. This means that people might experience more irritation when wearing several portable devices. The amount of annoyance reported by cognitive impaired versus unaffected people differed significantly. Cognitive impaired people reported fewer annoyances compared to healthy subjects. No significant differences were found between gender.

Further studies should focus on the determination of the applicability of other portable measurement devices which were not assessed in this study. These future assessments should exactly be performed following the same procedure as this study. Since wearing multiple devices simultaneously lead to discomfort, it is recommended to investigate comfort issues with participants wearing only one portable device at the time. Since unaffected people reported more critically compared to cognitive impaired people, it is recommended to continue further research with unaffected participants only. In this study, only the acute comfort issues are addressed. Cognitive impaired people seem to have less comfort problems regarding the devices; however, the acceptance of the devices should be further investigated. Furthermore, participants wore the devices for a measurement period for two to eight hours. An assessment period of at least 24 hours (day and night) can reveal long-term comfort issues and should also be considered. 
No significant differences of annoyance between genders were found. This result will simplify the recruitment for participants for future field studies. Regarding the practical problems of the portable measurement devices, it is recommended to check whether the participant is still wearing the device properly. This can be done, for example, by supervising the participants intensively or by incorporating an automatic check in the portable devices (e.g. measuring heart rate or skin temperature).

The current study shows that comfort and practical issues both need to be considered in the process to select a portable light measurement device for a study investigating the non-image-forming effects of luminous radiation. Consideration of the potential uncertainties and inaccuracies possibly caused by practical and comfort issues from the portable devices is recommended.

Gathering scientifically approved data using the developed research process will clarify both, the potential clinical impact of luminous exposure on NIF-effects (as described in (1) and (2)) and the engineering impact on performing NIF-effect field studies (as highlighted in (5) and (6)). The developed research process will help collecting useful and comparable data to draw conclusions from future studies performed by various research groups.

\section{Acknowledgments}

We would like to thank the Chair of Intellectual Disability Medicine of the Erasmus Medical Center Rotterdam and health care provider for people with intellectual disabilities Middin for their collaboration in experiments 1 and 2 , and all participants who participated in the three experiments. In addition, Daniel Garside, working at the University of Westminster in London, is recognized for his contributions in academic English and Christel de Bakker, a Ph.D. candidate in the building lighting group at the Eindhoven University of Technology, is recognized for her contributions in the statistical checks. 


\section{Funding statement or declaration of conflicting interests}

The authors received no financial support for the research, authorship, and/or publication of this article. The authors declare that there is no conflict of interest.

\section{References}

1. 1. Forbes D, Blake C, Thiessen E, Peacock S, Hawranik P. Light therapy for improving cognitive, sleep, functional, behavioural or mood disturbances in dementia: A Cochrane review. Alzheimer's Dement [Internet]. Elsevier Ltd; 2013;(1)(4):P661-2. doi: 10.1016/j.jalz.2013.05.1360

2. Duijnhoven J van. The development of a method to measure "circadian light " on the eyes of people with intellectual disability and elderly people suffering from dementia - A literature study. Master Thesis. Eindhoven University of Technology. 2015.

3. CIE. TN 002:2014 Relating Photochemical and Photobiological Quantities to Photometric Quantities. 2014.

4. CIE. TN 003:2015 Report on the First International Workshop on Circadian and Neurophysiological Photometry, 2013. 2015.

5. Hoof, J. van, Westerlaken, A.C., Aarts, M.P.J., Wouters, E.J.M., Schoutens, A.M.C., Sinoo, M.M. \& Aries MBC. Light therapy : methodological issues from an engineering perspective. Technol Heal Care [Internet]. 2012;20(1):11-23. doi: 10.3233/THC-2011-0650.

6. Aarts MPJ, Aries MBC, Diakoumis A, van Hoof J. Shedding a Light on Phototherapy Studies with People having Dementia: A Critical Review of the Methodology from a Light Perspective. Am J Alzheimers Dis Other Demen [Internet]. 2016 Mar 14. doi: 10.1177/1533317515628046

7. Markvart J, Hansen ÅM, Christoffersen J. Comparison and Correction of the Light Sensor Output from 48 Wearable Light Exposure Devices by Using a Side-by-Side Field Calibration Method. LEUKOS [Internet]. 2015 Apr 2;11(3):155-71. doi: 10.1080/15502724.2015.1020948

8. Kim J, de Dear R, Cândido C, Zhang H, Arens E. Gender differences in office occupant perception of indoor environmental quality (IEQ). Build Environ [Internet]. 2013 Dec;70:245- 
56. doi: 10.1016/j.buildenv.2013.08.022

9. Maaskant M, Wouw E. van de, van Wijck R, Evenhuis HM, Echteld MA. Circadian sleep-wake rhythm of older adults with intellectual disabilities. Res Dev Disabil [Internet]. 2013 Apr; 34(4):1144-51. doi: 10.1016/j.ridd.2012.12.009

10. Wouw, E. van de, Evenhuis HM, Echteld MA. Objective assessment of sleep and sleep problems in older adults with intellectual disabilities. Res Dev Disabil [Internet]. 2013 Aug;34(8):2291-303. doi: 10.1016/j.ridd.2013.04.012

11. Evenhuis Heleen M. Gezond ouder met een verstandelijke beperking [Internet]. 2014. Available from: http://onbeperktgezond.nl/wp-content/uploads/2014/03/RapportGOUD2014-def.pdf

12. CCMO (Centrale Commissie Mensgebonden Onderzoek). Your research: does it fall under the WMO [Internet]. Available from: http://www.ccmo.nl/en/your-research-does-it-fall-underthe-wmo

13. Hilgenkamp TIM, Bastiaanse LP, Hermans H, Penning C, van Wijck R, Evenhuis HM. Study healthy ageing and intellectual disabilities: Recruitment and design. Res Dev Disabil [Internet]. 2011 May;32(3):1097-106. doi: 10.1016/j.ridd.2011.01.018

14. Figueiro MG, Hamner R, Bierman A, Rea MS. Comparisons of three practical field devices used to measure personal light exposures and activity levels. Light Res Technol [Internet]. 2013 Aug; 45(4):421-34. doi: 10.1177/1477153512450453

15. Hubalek S, Zoschg D, Schierz C. Ambulant recording of light for vision and non-visual biological effects. Light Res Technol [Internet]. 2006 Dec 1;38(4):314-21.

doi: $10.1177 / 1477153506070687$ 


\section{Tables}

Table 1: Median deviations from measured luminous radiation at specific locations to the measured luminous radiation at the reference location at the eye.

\begin{tabular}{|l|l|l|l|l|l|l|}
\multicolumn{2}{c|}{ Wrist Indoor } & Outdoor & Indoor & Outdoor & Indoor & Outdoor \\
\hline Deviation from measured & & & & & \\
luminous radiation at specific & & & & & \\
location compared to & 26.3 & 12.7 & 16.6 & 6.7 & 7.2 & \\
measured luminous radiation & & & & & & \\
at the reference location [\%] & & & & & \\
\hline
\end{tabular}


Table 2: The total number of reported annoyances from all portable devices - Experiment 1

\begin{tabular}{|l|l|l|}
\hline $\begin{array}{l}\text { Total number of } \\
\text { annoyances }\end{array}$ & \multicolumn{2}{|l|}{$\begin{array}{l}\text { Number of participants experiencing this total } \\
\text { number of annoyances (frequency, percentage) }\end{array}$} \\
\hline 0 & 2 & $9,5 \%$ \\
\hline 1 & 5 & $23,8 \%$ \\
\hline 2 & 10 & $47,6 \%$ \\
\hline 3 & 4 & $19,0 \%$ \\
\hline Total & 21 & $100,0 \%$ \\
\hline
\end{tabular}


Table 3: Outcomes from Chi-square test for differences between groups for amount of annoyance from each device for each method $(A, B, C)-$ Experiment 2. (Values in table: $\chi^{2}(d f), p$-value, ${ }^{*}$ indicates a $p$ value<.05)

\begin{tabular}{|c|c|c|c|c|c|c|}
\hline & \multicolumn{2}{|c|}{ Method A (participant) } & \multicolumn{2}{|c|}{ Method B (caregiver) } & \multicolumn{2}{|c|}{ Method C (observations) } \\
\hline & $\begin{array}{l}\text { Annoyance } \\
\text { device } 1\end{array}$ & $\begin{array}{l}\text { Annoyance } \\
\text { device } 5\end{array}$ & $\begin{array}{l}\text { Annoyance } \\
\text { device } 1\end{array}$ & $\begin{array}{l}\text { Annoyance } \\
\text { device } 5\end{array}$ & $\begin{array}{l}\text { Annoyance } \\
\text { device } 1\end{array}$ & $\begin{array}{l}\text { Annoyance } \\
\text { device } 5\end{array}$ \\
\hline $\begin{array}{l}\text { Gender } \\
(\mathrm{M} / \mathrm{F})\end{array}$ & $\begin{array}{l}\chi^{2}(1)=1.500 \\
p=.221\end{array}$ & $\begin{array}{l}\chi^{2}(1)=0.875 \\
, p=.350\end{array}$ & $\begin{array}{l}\chi^{2}(1)=4.444 \\
p=.035^{*}\end{array}$ & $\begin{array}{l}\chi^{2}(1)=0.741 \\
p=.389\end{array}$ & $\begin{array}{l}\chi^{2}(1)=0.225 \\
p=.635\end{array}$ & $\begin{array}{l}\chi^{2}(1)=0.741 \\
p=.389\end{array}$ \\
\hline $\begin{array}{l}\text { Diagnosis } \\
\text { (ID/Dementia) }\end{array}$ & $\begin{array}{l}\chi^{2}(1)=0.000 \\
p=1.00\end{array}$ & $\begin{array}{l}\chi^{2}(1)=1.556 \\
, p=.212\end{array}$ & $\begin{array}{l}\chi^{2}(1)=0.278 \\
p=.598\end{array}$ & $\begin{array}{l}\chi^{2}(1)=1.667 \\
p=.197\end{array}$ & $\begin{array}{l}\chi^{2}(1)=0.225 \\
p=.635\end{array}$ & $\begin{array}{l}\chi^{2}(1)=1.667 \\
, p=.197\end{array}$ \\
\hline
\end{tabular}


Table 4: Outcomes from Chi-Squared Test for differences between groups (experiment 1, 2A/B/C, 3) for amount of annoyance from each device. (Values in table: $\chi^{2}$ value (df), $p$-value, ${ }^{*}$ indicates a $p$ value $<.05$, number of responses taken into account)

\begin{tabular}{|c|c|c|c|}
\hline & & Annoyance device 1 & Annoyance device 5 \\
\hline$\ddot{n}$ & $1,2 A, 3$ & $\chi^{2}(2)=5.504, p=.064, n=6$ & $\chi^{2}(2)=1.874, p=.392, n=10$ \\
\hline$\frac{\frac{d}{0}}{\frac{\pi}{3}}$ & $1,2 B, 3$ & $\chi^{2}(2)=4.482, p=.106, n=9$ & $\chi^{2}(2)=1.793, p=.408, n=10$ \\
\hline 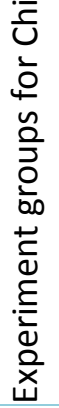 & $1,2 C, 3$ & $\chi^{2}(2)=4.482, p=.106, n=9$ & $\chi^{2}(2)=1.793, p=.408, n=10$ \\
\hline
\end{tabular}




\section{Figure captions}

Figure 1: Portable measurement devices on a participant - Experiment 1

Figure 2: Distribution portable measurement devices worn by participants - Experiment 3

Figure 3: Measured Illuminances from portable devices worn by 1 participant. Two of the three wristworn devices show relatively low output values (10:30-11:15) - Experiment 1.

Figure 4: Measured Illuminances from portable devices worn by 1 participant. The device as badge shows relatively low output values when the other devices show high illuminance values (15:00-15:15)

- Experiment 1.

Figure 5: Total number of reported annoyances for different devices - Experiment 1

Figure 6: Number of people experiencing annoyances from different devices, separated for participants with dementia and participants with ID - Experiment 2 


\section{Figures}

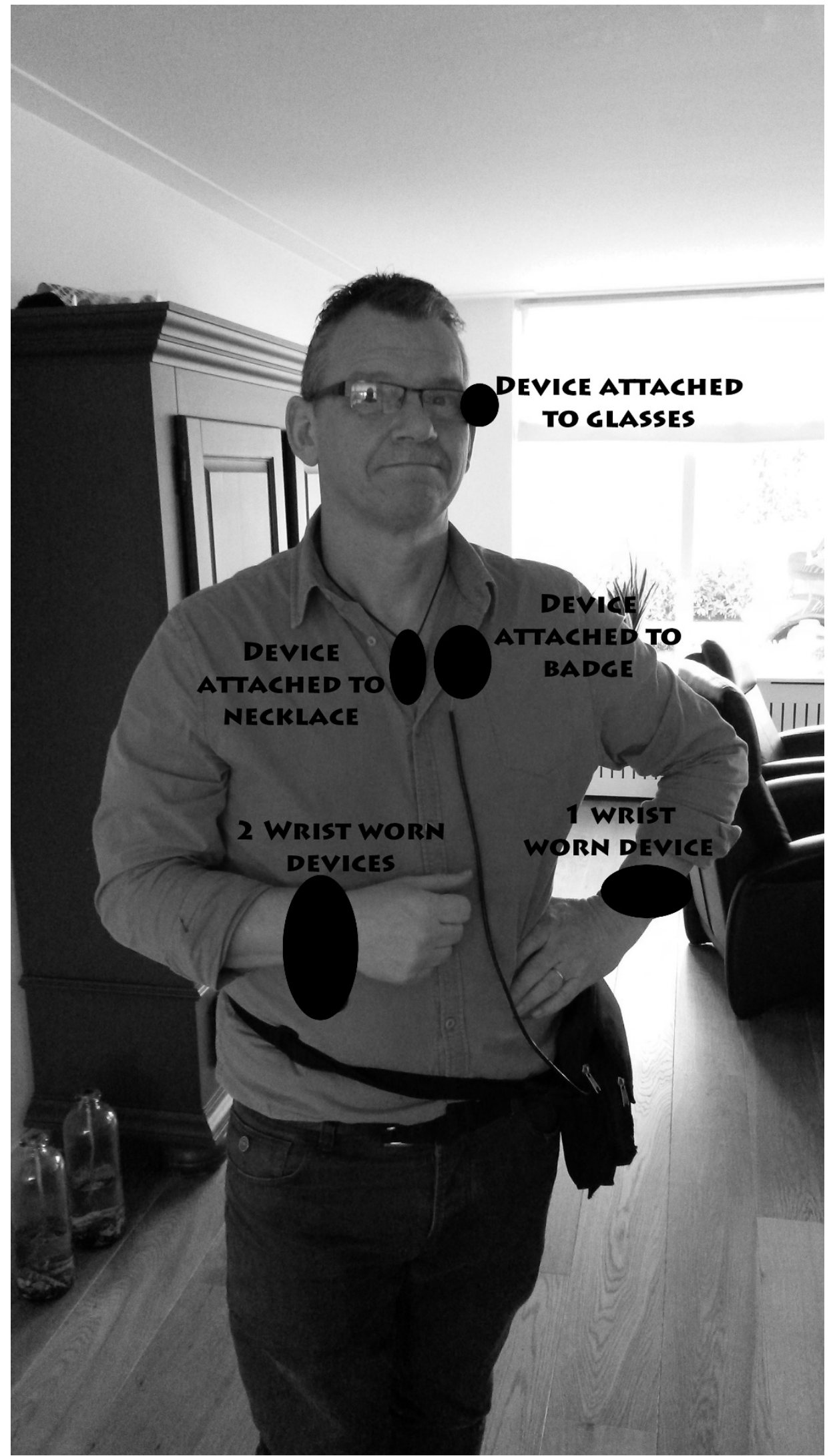




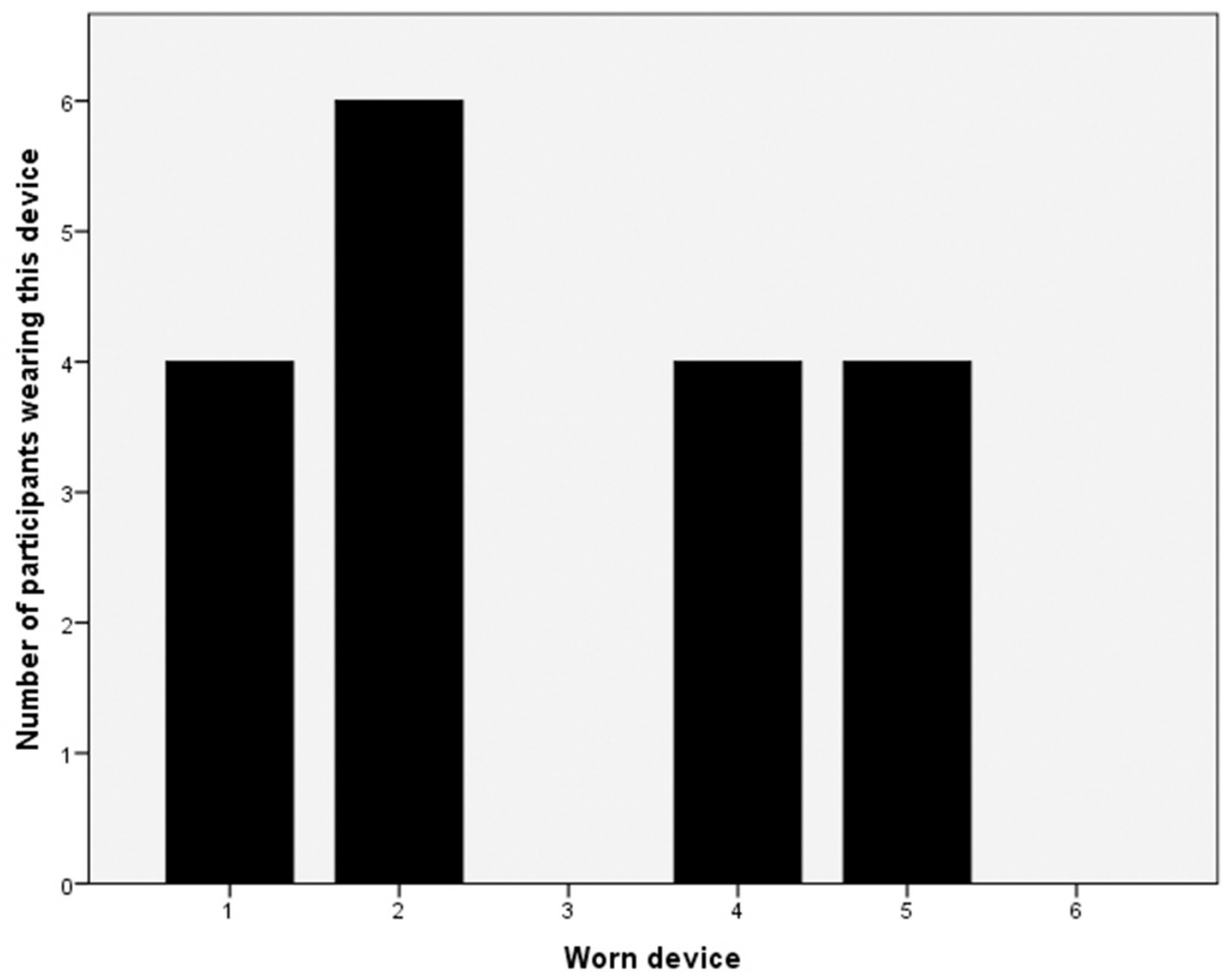




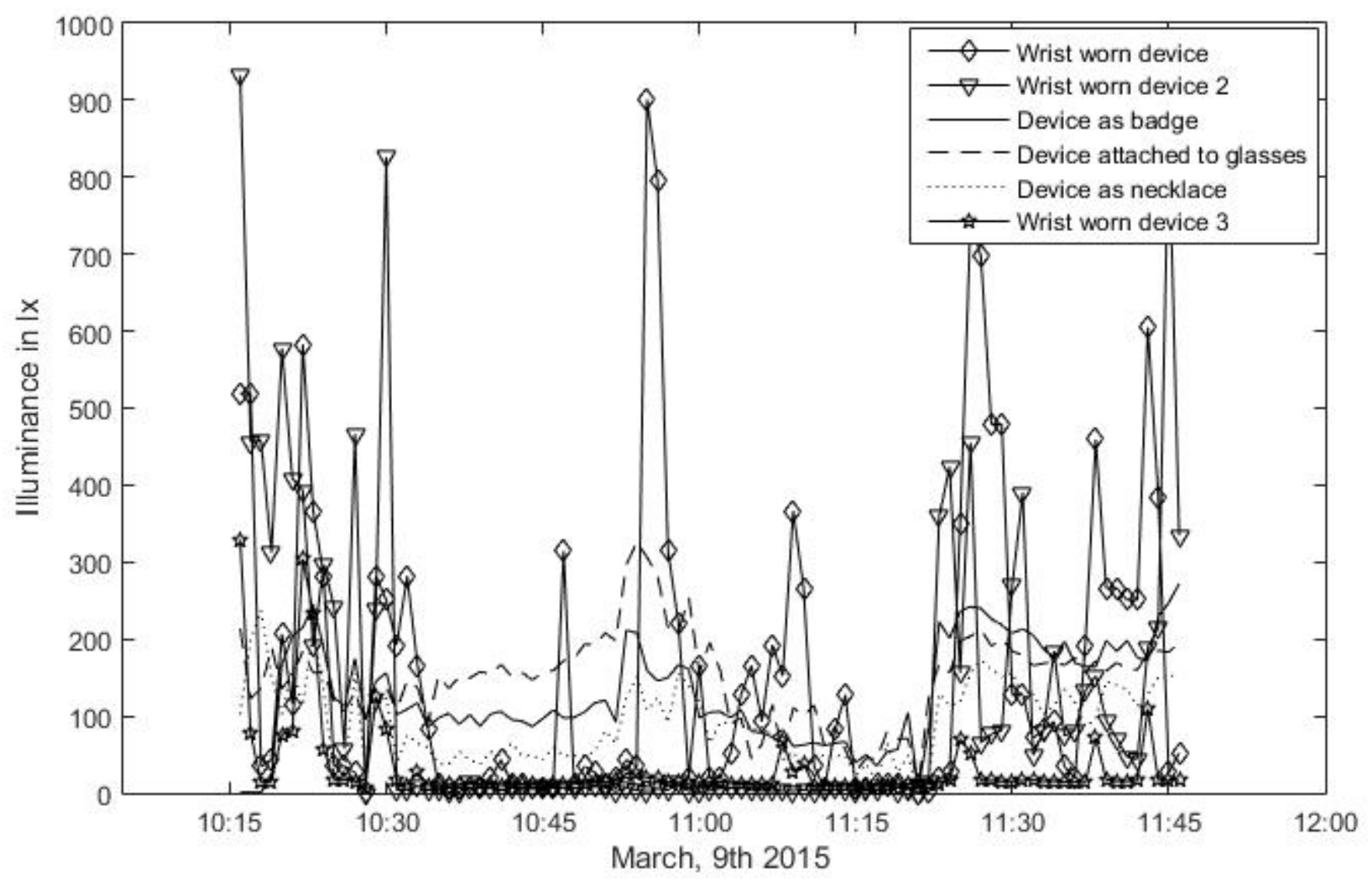




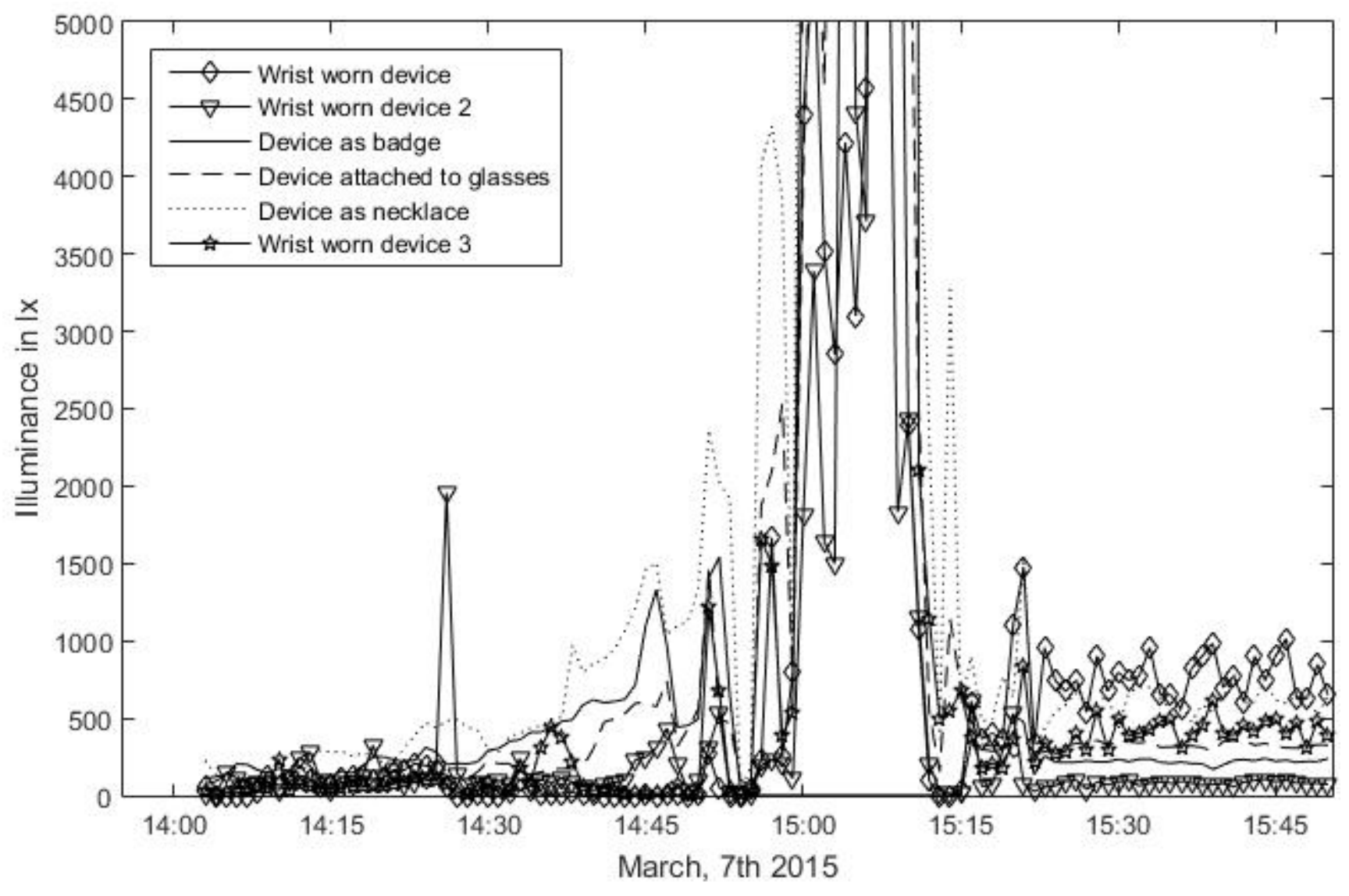




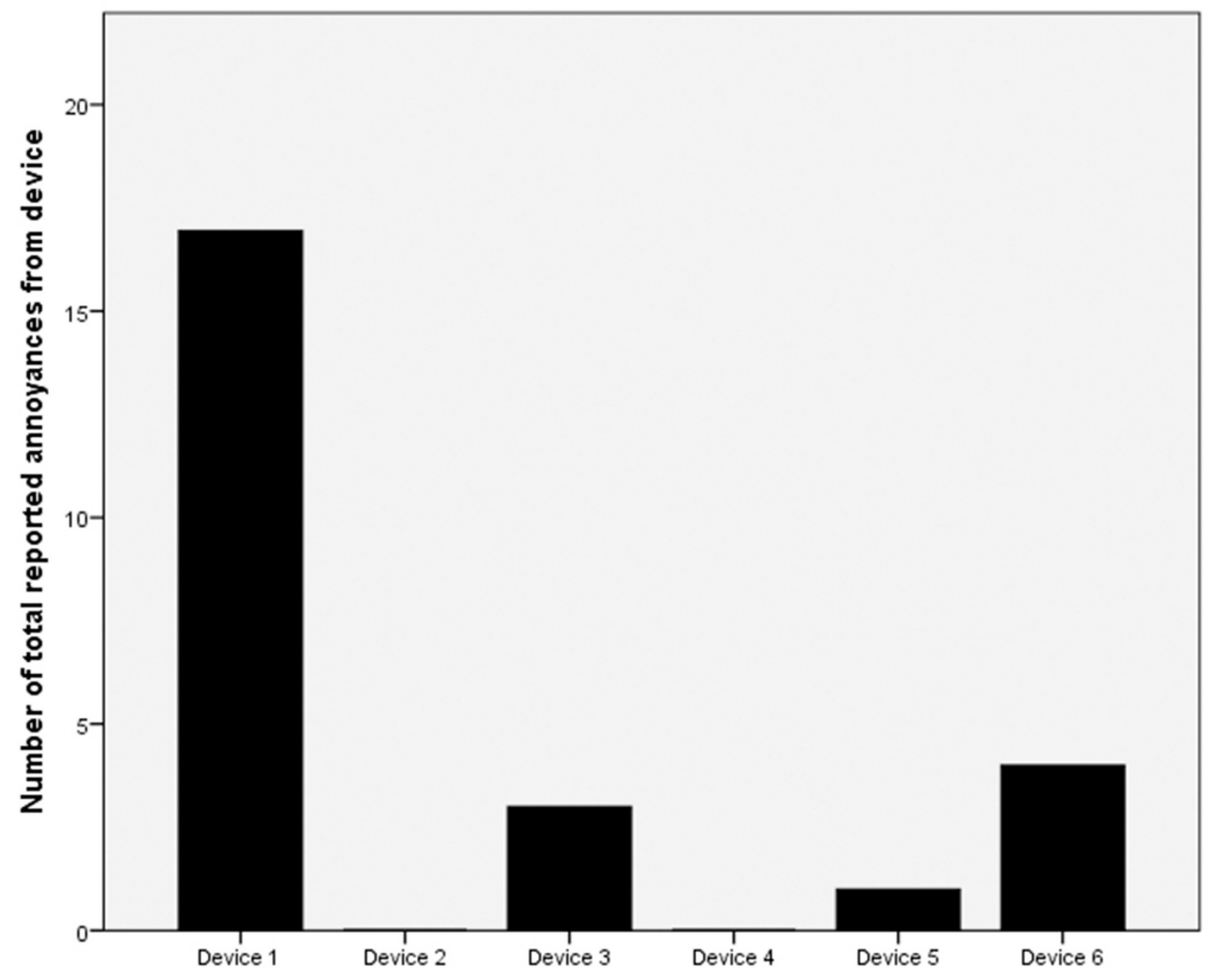




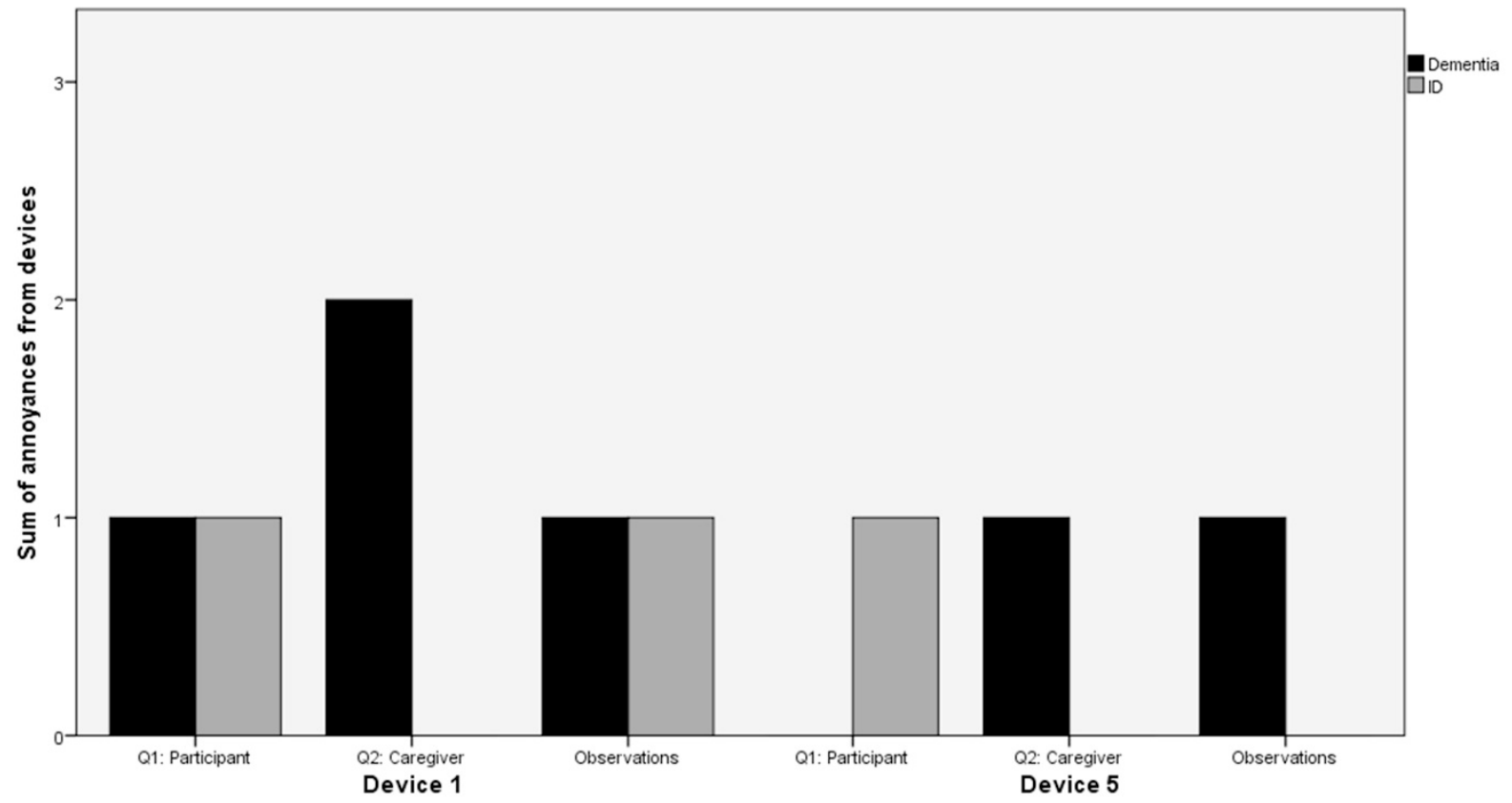

